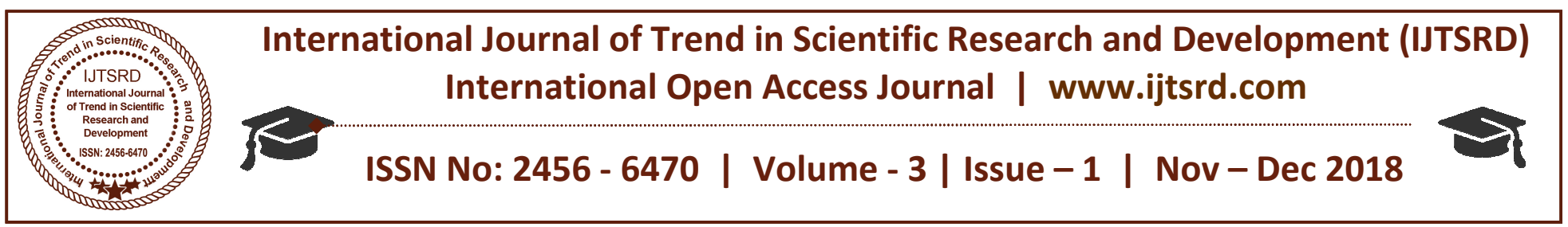

\title{
Analysis of Cycloconverter Fed Induction Motor Drive
}

\author{
Aye Aye Nyein \\ Department of Electrical Power Engineering, \\ Technological University, Thanlyin, Myanmar
}

\section{ABSTRACT}

This project is designed to control the speed of a single phase induction motor by using cycloconvertor technique by traics. Induction motors in particular are very robust and therefore used in many domestic appliances such as washing machines, vacuum cleaners, water pumps, and used in industries as well. A.C. motors have the great advantages of being relatively inexpensive and very reliable. The induction motor is known as a constant-speed machine, the difficulty of varying its speed by a cost effective device is one of its main disadvantages. The speed of the motor can be varied in two ways, one is by changing the number of poles and the second method is by changing the frequency. The speed control through the first method is uneconomical and the number of poles can't be varied under running conditions and the size of the machine also becomes bulky. These problems can be overcome by the second method. In this method, the frequency can be varied under running conditions also and there is no change in the size of the motor. In this method, the frequency changing device is cycloconverter. A cycloconverter is a power electronic device used to convert constant voltage constant frequency AC power to adjustable voltage adjustable frequency $\mathrm{AC}$ power without a DC link. In among all the methods this method is simple, reliable and economical. A pair of slide switches is provided to select the desired speed range (f, $f / 2, f / 3, f / 4$ and $f / 5)$ of operation of the induction motor. These switches are interfaced to the microcontroller. The microcontroller used for this project is from PIC18 family (PIC18F4550). The status of the switches enables the microcontroller to deliver the pulses to trigger the traic in a dual bridge. Thus, the speed of the induction motor can be achieved in five steps i.e. (f, $f / 2, f / 3, f / 4$ and $f / 5$ ).

KEY WORDS: Cycloconverter, Induction Motor, Microcontroller, Supply Frequency

\section{INTRODUCTION}

With the increasing motor loads for industrial applications the concept of energy saving has become vital. About $70 \%$ of the electrical loads are motor loads. Hence, the requirement of energy savings in electric drives is achieved through power electronic converters.

Variable frequency drives are mostly used for controlling either the torque or the speed of the AC motor. Applications such as pumps, centrifugal fan use the technique of variable frequency to achieve variable speed and variable torque. Variable frequency in $\mathrm{AC}$ drives can be achieved by inverter fed or cycloconverter fed drives. The advantage of cycloconverter over inverter fed drive is its single stage conversion.

\section{CYCLOCONVERTER}

Cycloconverters are the direct type converters used in high power applications for driving induction and synchronous motors. Cycloconverters are usually phase-controlled device. Cycloconverter is a device which converts the $\mathrm{AC}$ power at one frequency input to a $\mathrm{AC}$ power at different frequency output.

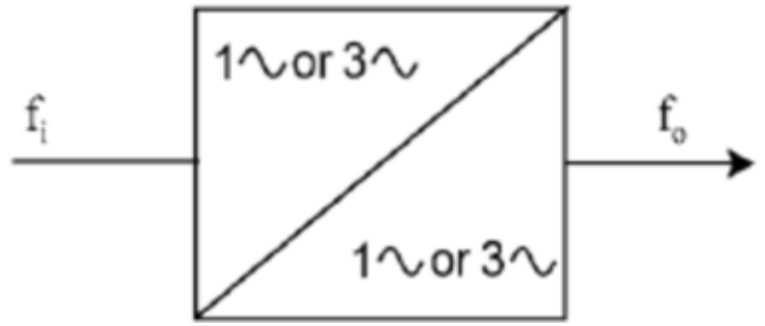

Figure.1 Cycloconverter

A cycloconverter is a type of power controller in which an alternating voltage at supply frequency is converted directly to an alternating voltage at load frequency without any intermediate DC stage. The cycloconverter also allows power to flow freely in either direction [3]. 
There are three types of cycloconverter: 1.Single Phase to Single phase cycloconverter. 2.Three Phase to Three Phase cycloconverter. 3.Single Phase to Three Phase cycloconverter

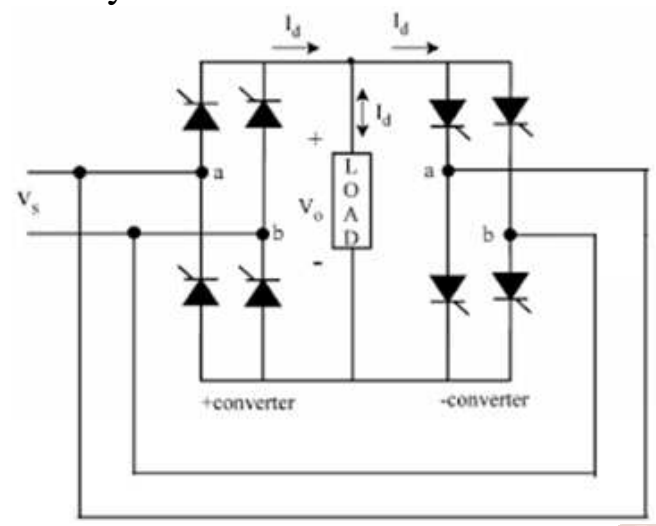

Figure.2 Single-Phase to Single-Phase Cycloconverter

\section{PROPOSED TOPOLOGY}

Cycloconverter is a power electronic circuit that converts fixed voltage fixed frequency input AC voltage to variable voltage yariable frequency output AC. The output frequency may be greater than input frequency (step up cycloconverter) or the output frequency may be less than the input frequency (step down cycloconverter).

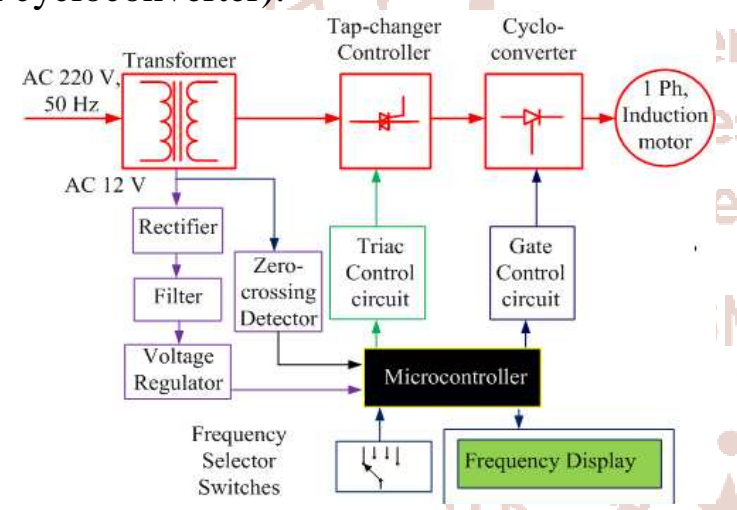

Figure.3 Block Diagram of Proposed Cycloconverter Controlled Induction Motor Drive

The block diagram for the traic controlled cycloconverter drive for controlling the speed of induction motor is shown in Fig. 3.

This traic controlled cycloconverter drive has following components: transformer, rectifier, filter, voltage regulator, zero-crossing detector, tap changer controller, triac control circuit, cycloconverter, microcontroller, frequency display and single phase induction motor.

Transformer: In this traic controlled cycloconverter drive, the transformer is used for step down the AC voltages and works on the principle of mutual induction. In this case, this would be step down the 220 VAC into 15 VAC.

Bridge Rectifier: This cycloconverter drive consists of electronics components which are operated on DC voltages therefore the $\mathrm{AC}$ voltages are converted into DC through bridge rectifier, which consists of four diodes and connected at the output of transformer.

Voltage Regulator: In this traic controlled cycloconverter drive, the voltage regulator is used for regulator the $\mathrm{DC}$ voltages which comes from the bridge rectifier. It regulates the $15 \mathrm{VDC}$ into $5 \mathrm{VDC}$ and for this purposes, the LM7805 voltage regulator are used.

Microcontroller PIC 18F4550: In this traic controlled cycloconverter drive the PIC 18F4550 microcontroller are used for the intelligent control of this drive. This microcontroller controls the firing angle of the traic voltages for controlling the speed of motor in five steps. It is powered up with $5 \mathrm{VDC}$ and interfaced with the optocouplers. It is 40 pins microcontroller and programmed in $\mathrm{C}$ language with the help of mikro/C software.

Zero-Crossing Detector: The microcontroller has been programmed i.e. C program to give output to optical isolation with zero cross detection circuit. It compares two signals in order to get zero crossing whenever the zero crossing occurs it gives an output.

Mode Selection: In this drive the selection mode is basically the switch, which is used for the selection of frequency and this drive is designed for five frequency steps.

Motor: In this traic, controlled cycloconverter drive, the single-phase AC induction motor is controlled through this drive which is basically the inductive load.

The working principle of the traic controlled cycloconverter drive for controlling the speed of induction motor are as follows.

This traic controlled cycloconverter drive works on the principle of variable frequency drive, when the frequency is changed then the speed is also changed. In this paper, first the single-phase induction motor is driven at fundamental frequency which is $50 \mathrm{~Hz}$, then at $\mathrm{f} / 2 \mathrm{~Hz}$ and then $\mathrm{f} / 3 \mathrm{~Hz}, \mathrm{f} / 4 \mathrm{~Hz}$ and $\mathrm{f} / 5 \mathrm{~Hz}$ 
respectively. At fundamental frequency, the motor runs at its full speed which could be checked by the tachometer, then it would be drive at $\mathrm{f} / 2$ then the motor runs at half speed and then motor is drive at $f / 3$, at this frequency the motor speed could be quarter. This drive consists of switch which is for frequency selection mode.

The microcontroller basically increase or decrease delay time of the trigging signal, which is inversely proportional to the speed of the single-phase motor. The delay time is set in microcontroller through programming.

\section{PERFORMANCE ANALYSIS SIMULATION RESULTS}

AND

Accurate simulation of electrical and electronic control systems would save many hours of prototype development. In this paper the Proteus Virtual System Modeller (VSM) software from Labcenter Electronics Ltd is used to provide such simulation environment. The Zero Crossing Detector Circuit for cycloconverter fed induction motor drive in Proteus Simulation is as shown in Fig. 4.

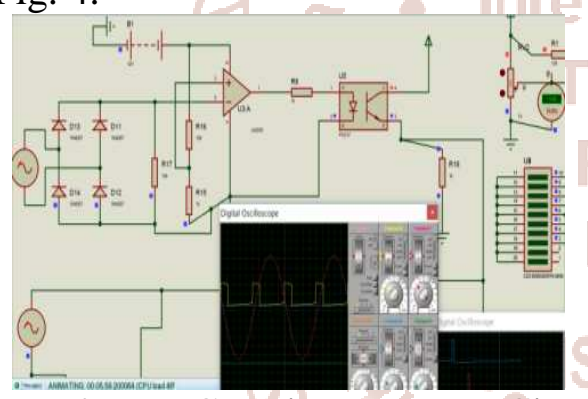

Figure.4 Zero Crossing Detector Circuit

In Fig. 5, the program flowchart for frequency (f) is described and simulation test result is shown in Fig. 6.

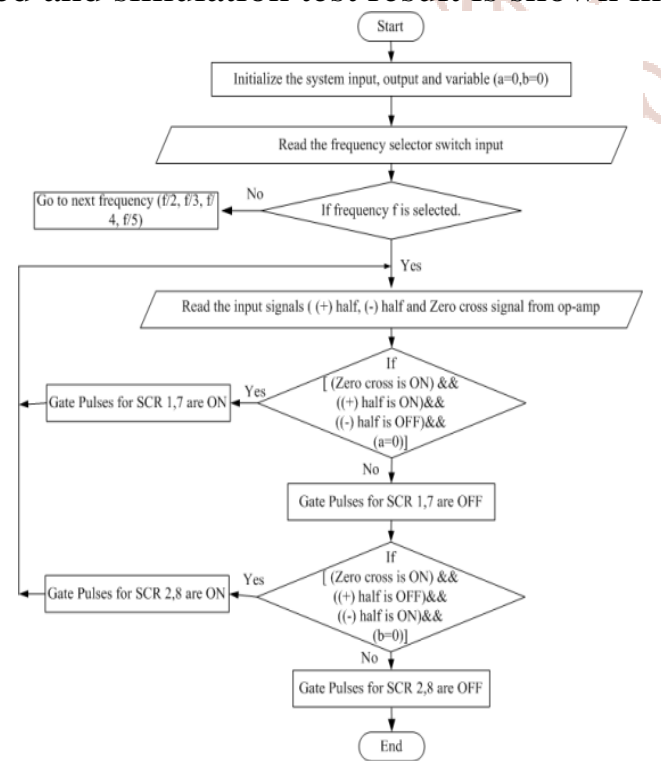

Figure.5 Program Flowchart for Frequency (f)

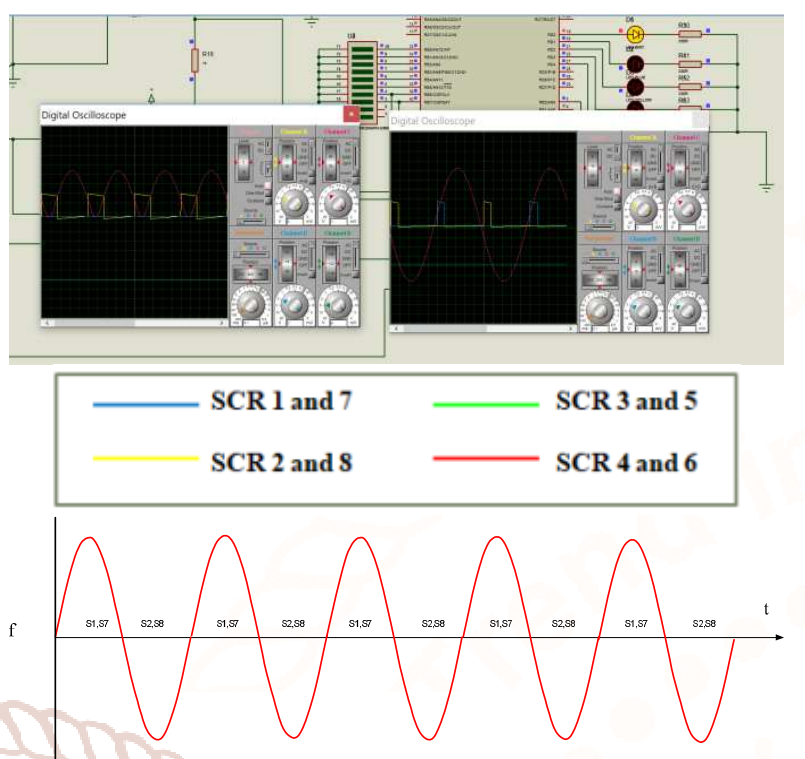

Figure.6 Simulation Test Result for Frequency (f)

In Fig. 7, the program flowchart for frequency (f/2) is described and simulation test result is shown in Fig. 8.

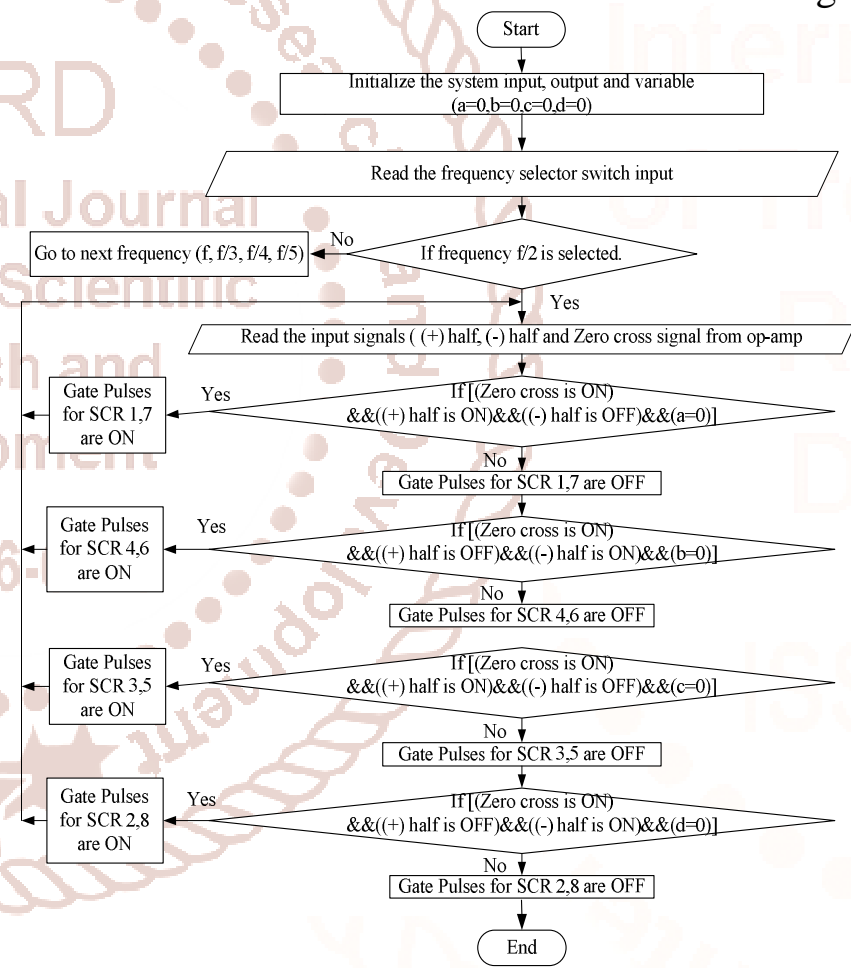

Figure.7 Program Flowchart for Frequency (f/2)

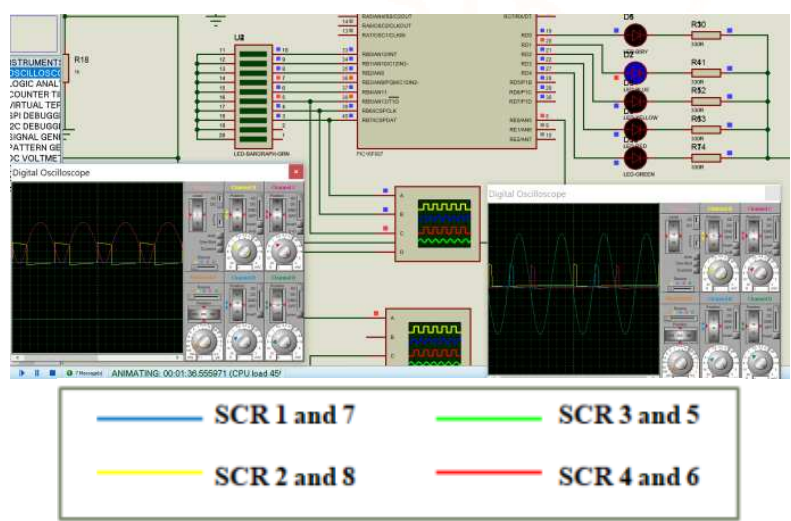


International Journal of Trend in Scientific Research and Development (IJTSRD) ISSN: 2456-6470

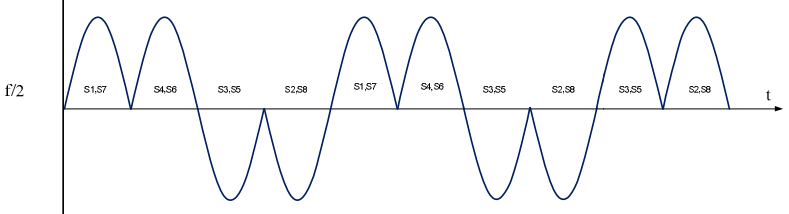

Figure.8 Simulation Test Result for Frequency (f/2)

In Fig. 9, the program flowchart for frequency (f/3) is described and simulation test result is shown in Fig. 10.

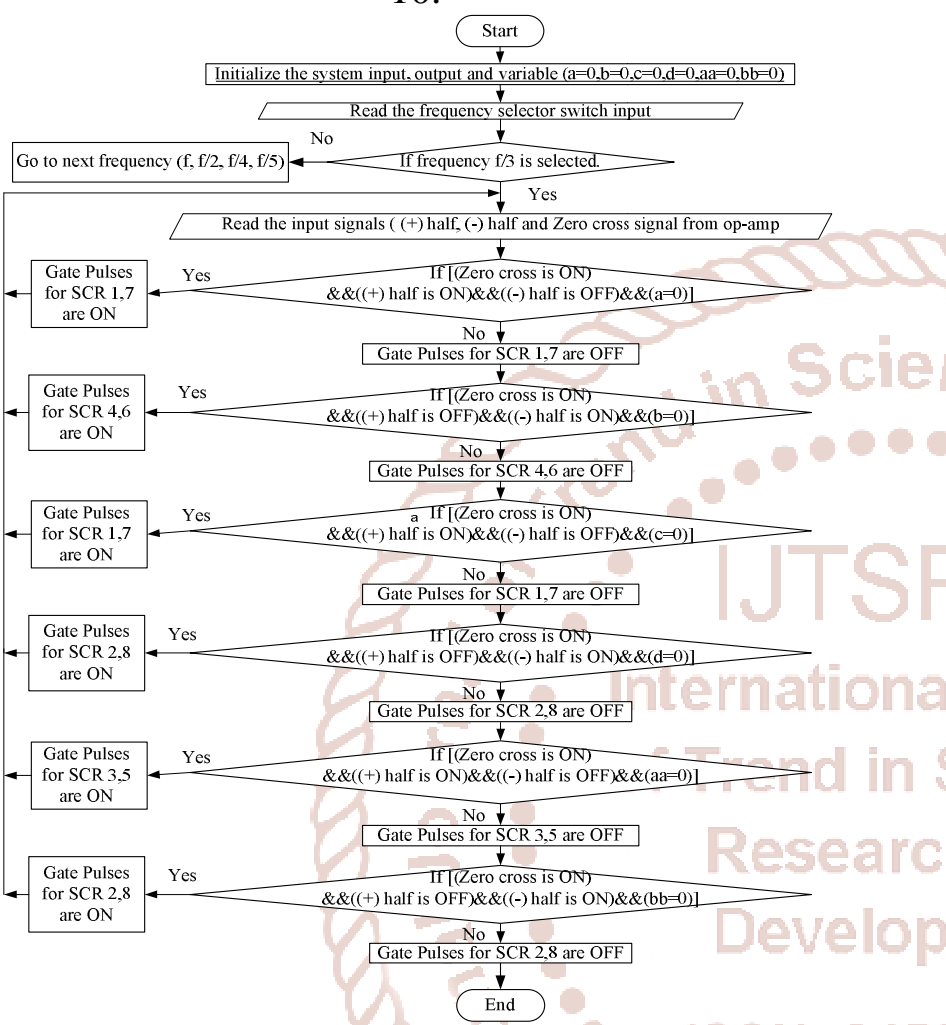

Figure.9 Program Flowchart for Frequency (f/3)

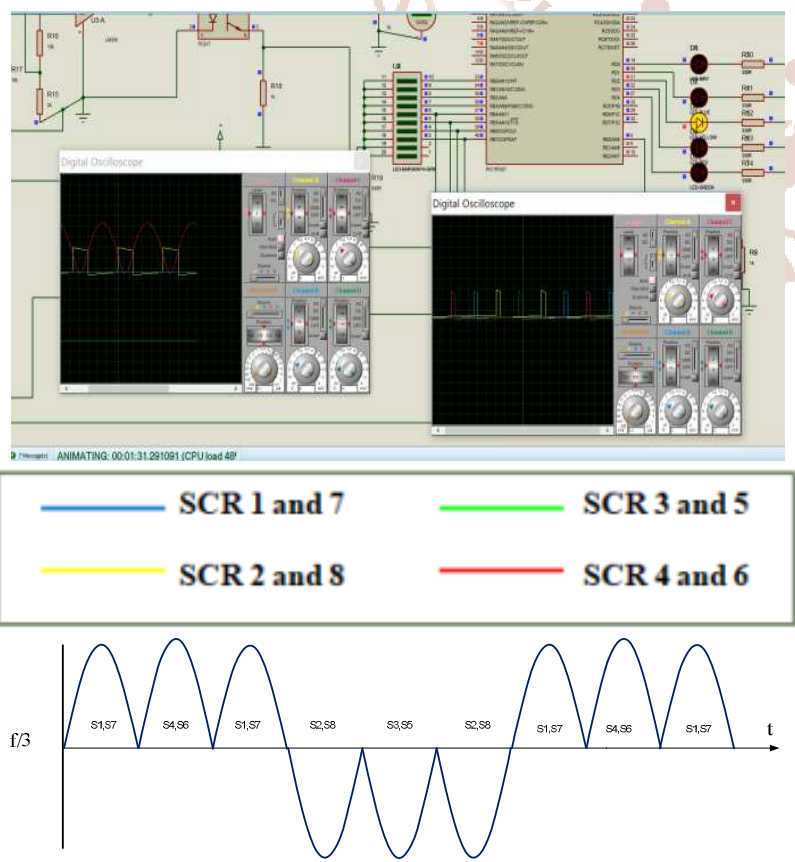

Figure.10 Simulation Test Result for Frequency (f/3)
In Fig. 11, the program flowchart for frequency (f/4) is described and simulation test result is shown in Fig.12.

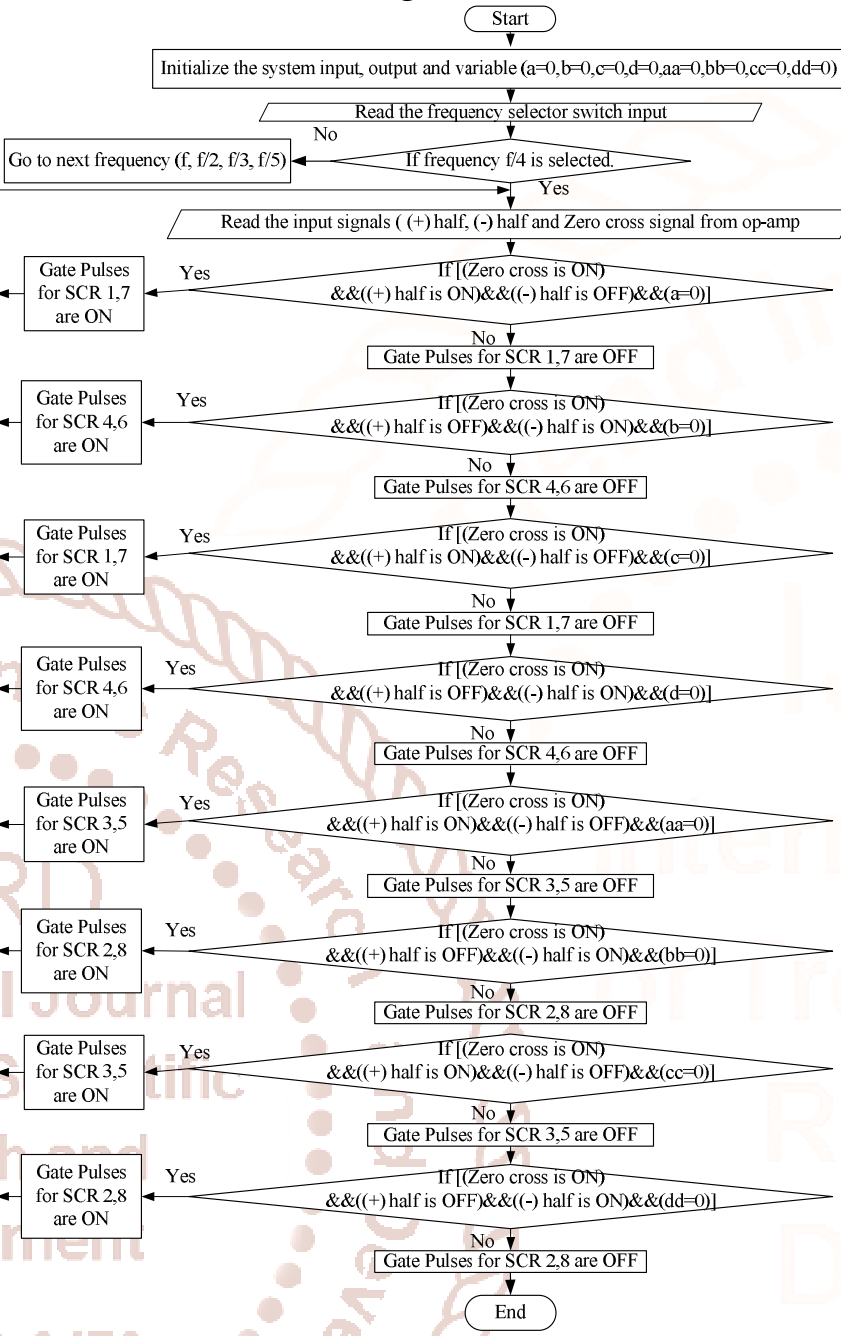

Figure.11 Program Flowchart for Frequency (f/4)

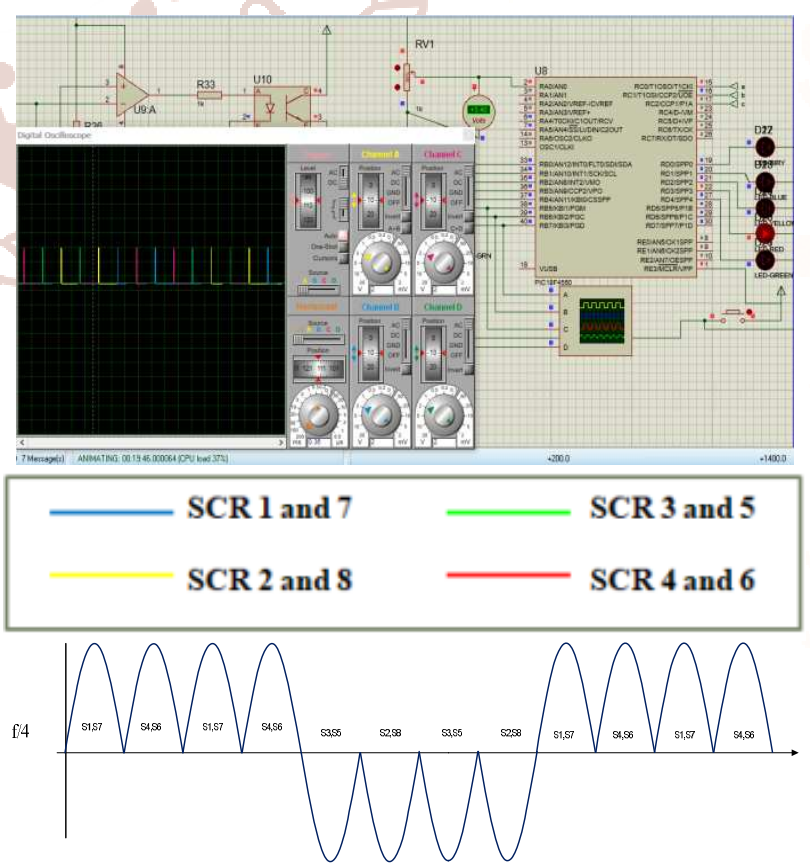

Figure.12 Simulation Test Result for Frequency (f/4) 
In Fig. 13, the program flowchart for frequency (f/5) is described and simulation test result is shown in Fig.

\section{4.}

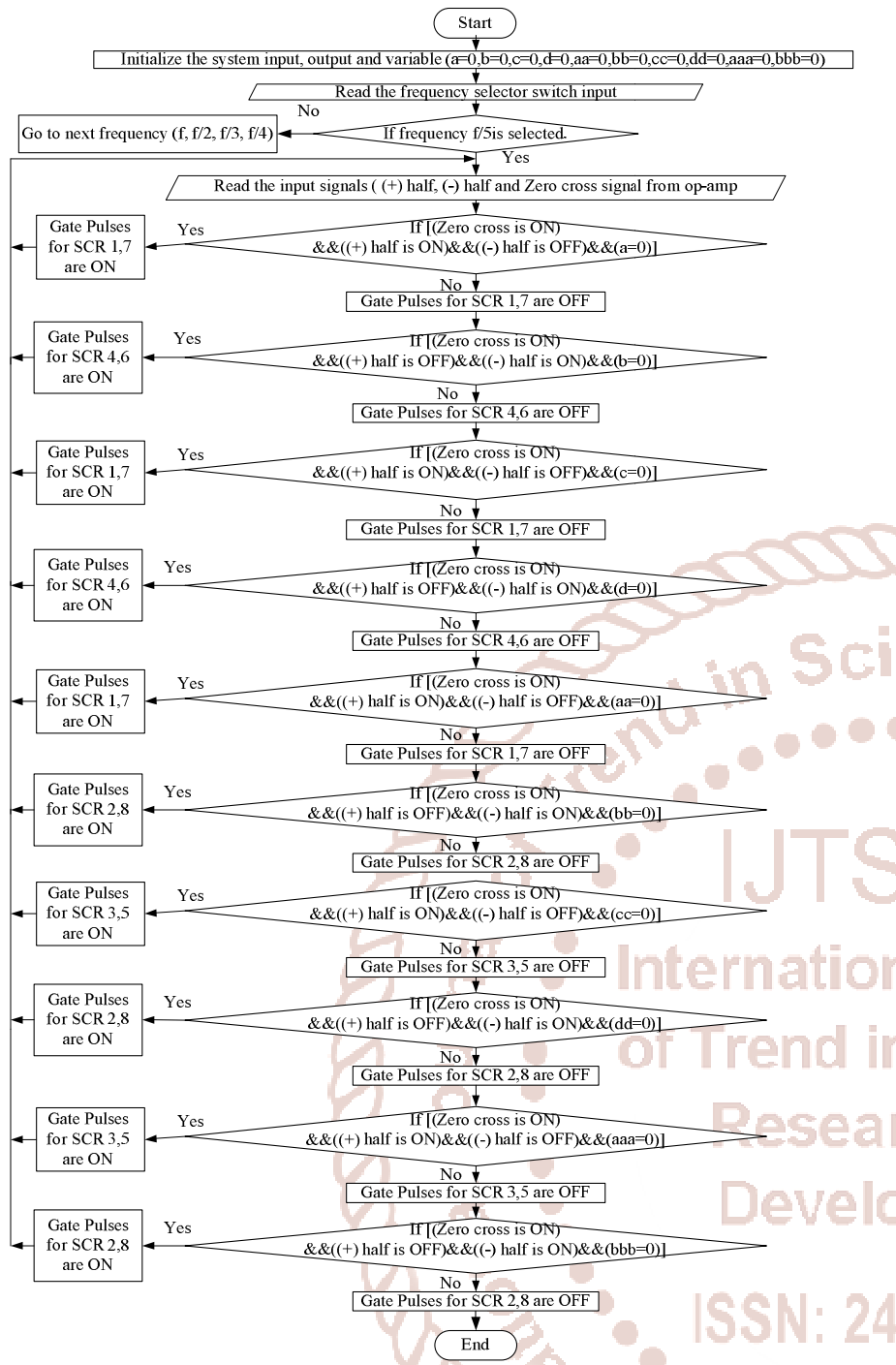

Figure.13 Program Flowchart for Frequency (f/5)
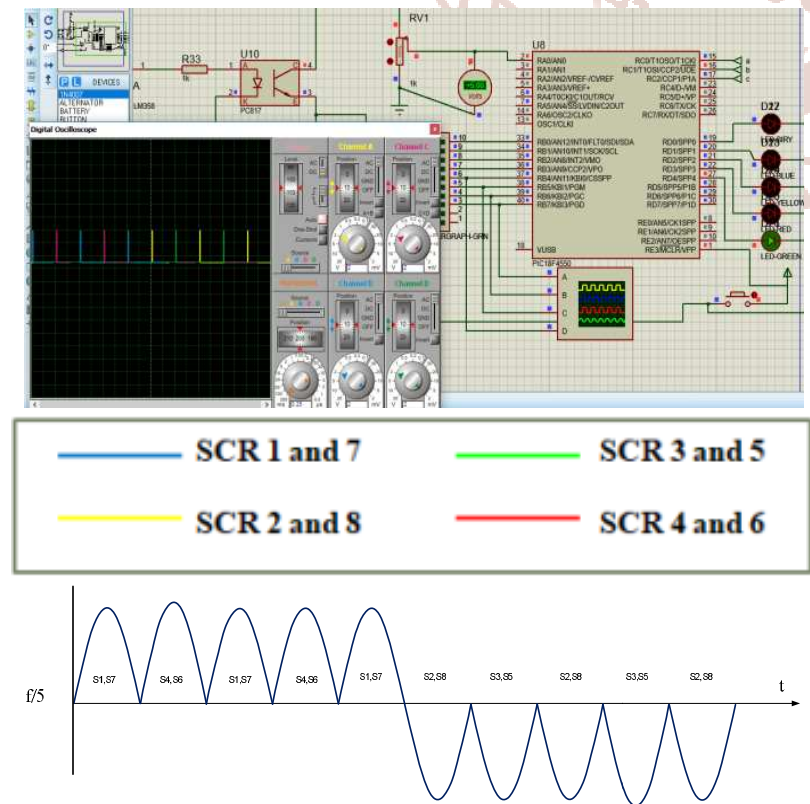

Figure.14 Simulation Test Result for Frequency (f/5)
In Fig. 15 and Fig. 16 shows the Proteus test results.

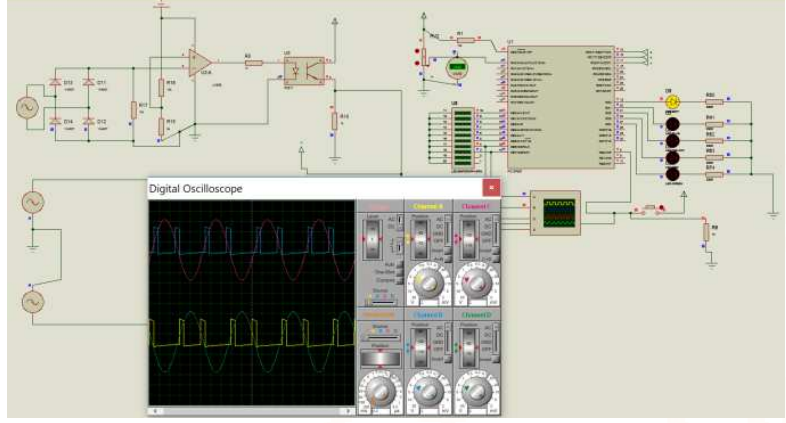

Figure.15 Proteus Test 1

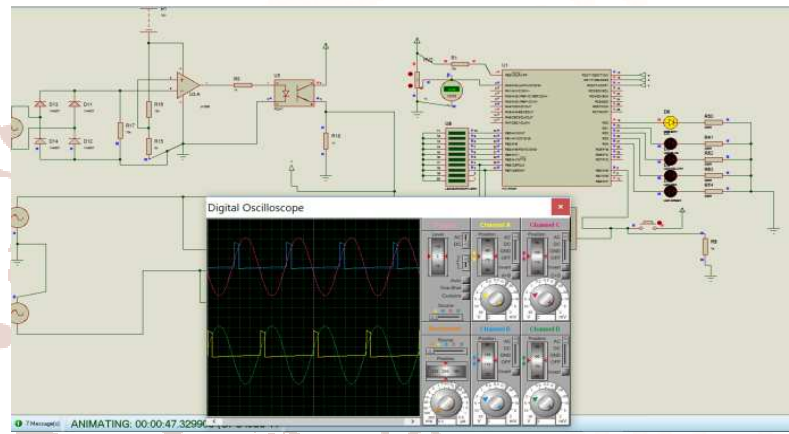

Figure.16 Proteus Test 2

\section{CONCLUSION}

A cycloconverter is a device use to convert a constant voltage constant frequency AC power to variable voltage variable frequency without any intermediate DC link. This paper presented a speed control of single phase induction motor by using single phase cycloconverter. There are several techniques used for conversion but order to have maximum converter utilization, special cycloconverter techniques have to be used. Cycloconverter circuit have been designed for speed control of induction motor for adjustable frequency. Single phase cycloconverter used to change the speed of induction motor with the help of microcontroller, different desired frequency is obtained to equalize the desired speed. This different frequency of cycloconverter is obtaind in the manner of adjustable speed to $f, f / 2, f / 3, f / 4$ and $f / 5$.

\section{ACKNOWLEDGMENTS}

The author would like to express her profound gratitude to Dr. Theingi, Rector, Technological University (Thanlyin), for her encouragement and managements and the author would like to express her thanks to thesis supervisor, Dr. Su Hlaing Myint, Professor of Electrical Power Engineering, for her motivation and encouragement to complete this research in time. After all, the author would like to express her thanks to all her teachers and her parents, for their supports and encouragements. 
International Journal of Trend in Scientific Research and Development (IJTSRD) ISSN: 2456-6470

\section{REFERENCES}

1. https://www.elprocus.com/cycloconverters-typesapplications/

2. https://ieeexplore.ieee.org/document/5533596

3. A Survey on Single Phase to Three Phase CycloConverter Fed Induction Motor; IJSRD - Vol. 3, Issue 10, 2015 ISSN

4. Survey on Thyristor Using Cyclo-converter (IRJET) e-ISSN:2395 005; Volume:03 Issue:04|APRIL-2016p-
0072@2016,IRJET ISO 9001:2008 Certified Journal

5. Speed Control of Induction Motor using Cycloconverter; International Journal of Engineering Trends and Technology (IJETT) Volume4 Issue4-April 2013.

6. A Review on Speed Control Techniques of Single Phase Induction Motor; International Journal of Computer Technology and Electronics Engineering (IJCTEE) Volume 2, Issue 5, October 2012.

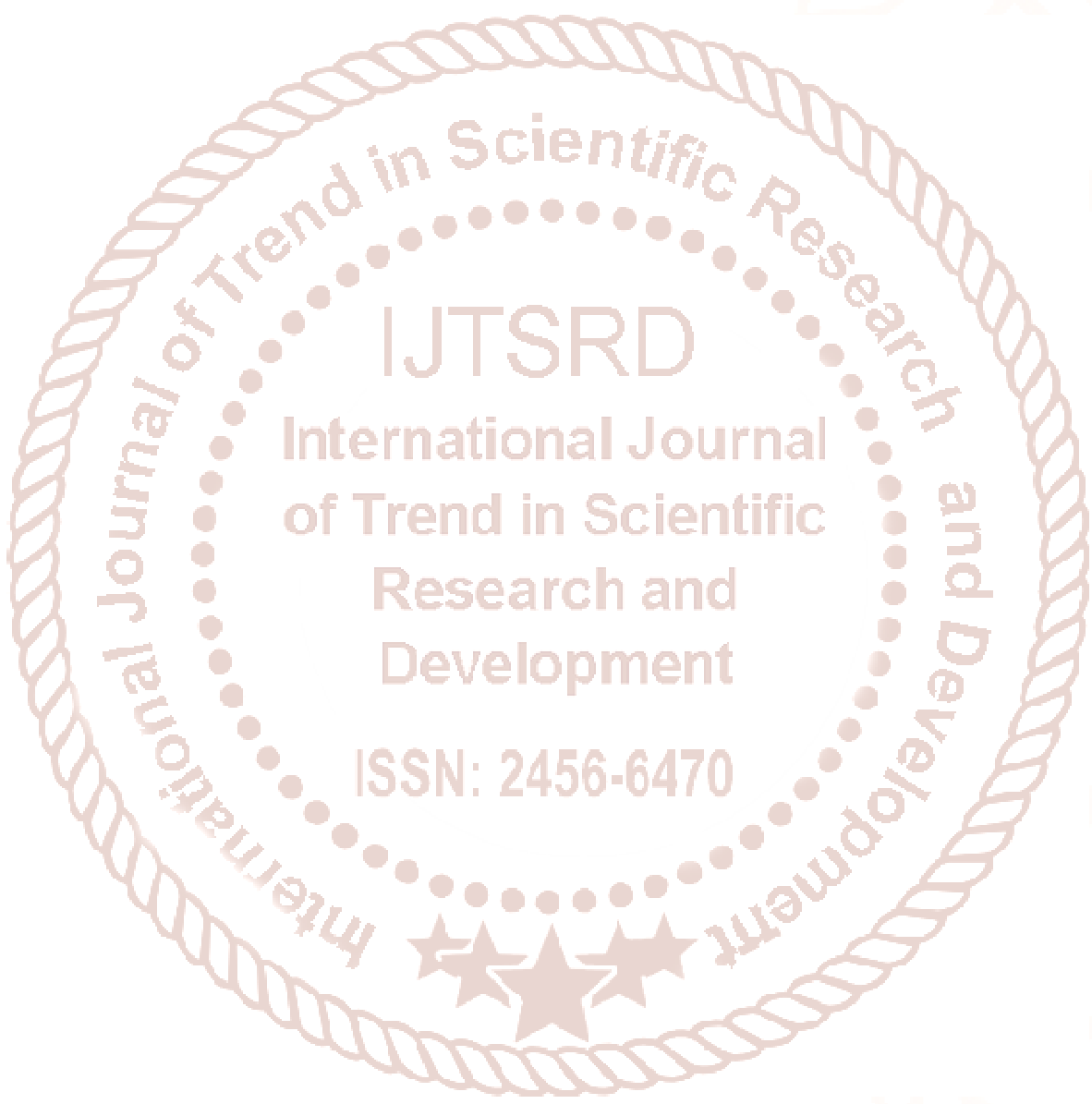

